\title{
Novel perceptions toward the pathology and treatment outcomes in lower back pain patients using wearable trackers
}

\author{
Sumihisa Orita ${ }^{1,2}$, Masahiro Inoue ${ }^{2,3}$, Kazuhide Inage ${ }^{2}$, Yasuhiro Shiga ${ }^{2}$, \\ Yawara Eguchi ${ }^{2}$, Satoshi Maki ${ }^{1,2}$, Takeo Furuya ${ }^{2}$, and Seiji Ohtori ${ }^{2}$ \\ ${ }^{1}$ Center for Frontier Medical Engineering, Chiba University \\ ${ }^{2}$ Department of Orthopaedic Surgery, Graduate School of Medicine, Chiba University \\ ${ }^{3}$ Department of Orthopaedic Surgery, Eastern Chiba Medical Center
}

Abstract

We analyzed patients' actual activity level with low back pain using a wristwatchshaped wearable trackers to find the correlation between the low back pain function and social life domains of the JOABPEQ and negatively correlated with the low back pain VAS, as well as a significantly shorter sleep time. Besides, the effect of lumbar spine surgery on activity level showed a tendency for activity level to decrease immediately after surgery and then to improve to show a different tendency compared with the traditional evaluation suggesting the limitations of conventional evaluation.

\section{次世代型の運動器疼痛解析 : ウエアラブル端末を用いた 客観的な腰痛の病態・手術治療効果評価の試みを通じて}

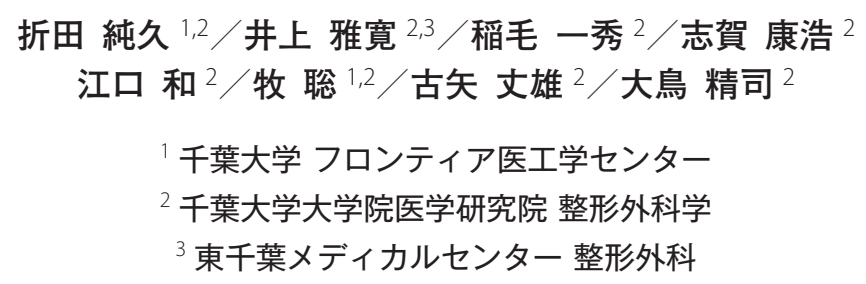

\section{はじめに}

腰痛は国民愁訴の最多を占め，その病態を正 確に把握・解析することはその正確な疫学・病 態の理解に加え, 今後の医療施策を効率化する
ためにきわめて重要である。しかしながらその 病態および治療効果の判定や評価はこれまでい くつかの段階を変遷してきた。患者の病態評価 は医師主体のスコア（JOA スコア）から患者立 脚型評価（JOABPEQ）が主流となって久しい 
ものの，根本的にはこのようなアンケート形式 の評価法では患者の正確な日常生活量まで全て を評価することは困難であり, 病勢・病態を完 全に反映しているとは言いがたい。すなわち現 状で腰椎疾患患者の状態や治療効果の評価に用 いられている患者立脚型アウトカム評価では, 患者の実際の客観的デー夕収集が困難であるこ とが最大の課題であり限界であった。我々はこ の課題に対する解決策のひとつとして, 患者が 装用し歩行, 臥位や運動量, バイタル変化など 患者の日常生活動作を客観的に収集蓄積できる ウエアラブル端末装置の応用に着目した。これ らの端末は従来のアンケート式の手法では収集 がほぼ不可能な日常生活量デー夕の記録・蓄積 が可能であり，その解析による腰痛評価はこれ までは得られなかった客観的な知見の導出が期 待される。ここでは我々が行ったウエアラブル 端末を用いて行った腰痛患者における活動量評 価解析について報告し，デー夕の客観性・エビ デンスを確保するため我々が導入した多施設レ ジストリ制度の導入の試みについて概説する。

\section{ウエアラブル端末の導入について}

今回行った研究では, 腕時計型小型高感度加 速度センサー (Actigraph; Ambulatory Monitors Inc., Ardsley, NY, USA）を用いた（Fig.1A）。 本端末は $0.01 \mathrm{G} / \mathrm{rad} / \mathrm{sec}$ 以上の加速度を検出し, 一日の体動推移が数值化され表示される 1)。こ こから 1 分間に平均体動数, および平均体動量 を算出する。この腕時計型ウエアラブル端末は これまで睡眠, リハビリテーション評価の領域 で使用され，その検出デー夕は睡眠時無呼吸症 候群の診断に用いられる睡眠ポリソムノグラ フィーに対しても約 $90 \%$ の相関を示すとされ る1)。腰痛患者においては非利き手の前腕およ
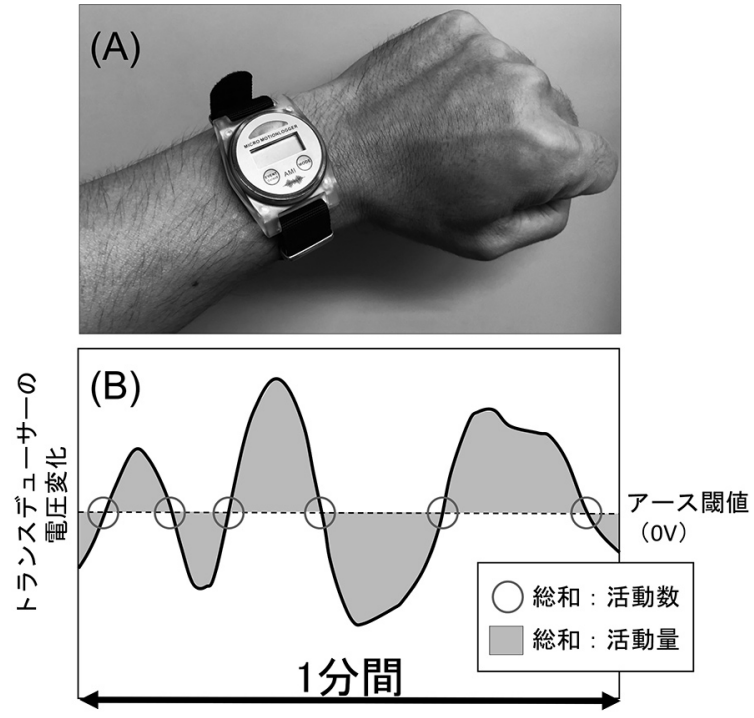

Fig.1 ウエアラブル端末 (アクチグラフ) の実際

(A) 腕時計型端末であり, 小型高感度加速度センサーに より一日の体動推移が数值化・記録される。

（B）アース閾値との干渉数を活動数とし，同閾値を基点 とした電位を積算して活動量を算出する。

び体幹に加速度計を同時装着しデー夕を収集， 腰痛患者と健常者の日中活動数㧍よび活動量 において腕と体幹のデータの相動性, 差異を 評価した結果, 前腕装着でも遜色なく活動度 が測れることがわかっている2)。本研究では平 均体動数を活動数, 平均体動量を活動量と定義 （Fig.1B）し, 腰痛患者の客観的デー夕に基づ き腰痛患者の活動度測定の妥当性と客観的デー 夕解析を行った ${ }^{3)}$ 。

\section{腰痛患者における活動量と患者立脚型 アウトカム, 体組成との関係 ${ }^{4}$}

まず腰痛患者における活動量の特徴について 調查するため, 3 か月以上続く慢性腰痛を呈す る腰椎変性疾患 70 例 (平均年齢 $70.6 \pm 9.1$ 歳) を対象とした（除外条件：独歩不可，四肢に明 らかな麻疩や歩行障害がある場合, 疼痛を生じ る関節症を有する場合，および精神疾患や認知 
障害を有する場合)。評価項目として活動数お よび 活動量と患者立脚型アウトカム (Japanese Orthopaedic Association Back Pain Evaluation Questionnaire (JOABPEQ), Oswestry Disability Index (ODI), Roland-Morris Questionnaire (RDQ)，VAS，患者因子 (年齢, 性別，Body Mass Index (BMI)), 体組成（生体インピーダ ンス法により計測した四肢筋量）との関係につ いて重回帰分析を用いて評価した。

その結果, JOABPEQの各ドメインについて 統計学的評価を行ったところ活動数については 患者立朋型アウトカムのいずれの項目でも相関 はみられなかったが, 腰椎機能, 社会生活と活 動量で相関を示し $(r=0.327, r=0.321 ; p<0.05)$, また腰痛 VAS 值と活動量に負の相関を認めた $(\mathrm{r}=-0.246 ; \mathrm{p}<0.05)$ 。これに加えて患者因子と 活動数・活動量の関係においては, 重回帰分析 において腰痛 VAS 值，性別（男性であること）, BMI 高值，四肢筋量の低下が活動量の低下に 有意な相関を認めた $(\mathrm{p}<0.01)$ 。

\section{腰椎手術前後における活動量変化 ${ }^{5)}$}

続いて当院で腰椎疾患に対し手術を行った 58 例を対象として，手術後の実際の活動量につい て評価した。術直前，術後 $1,3,6,12$ か月の活動 量，患者立脚型アウトカム（JOABPEQ, ODI, RDQ, VAS）を測定し，各測定時期における変 化を評価した。また術前因子 (年齢，性別，罹 患期間，VAS，BMI，体幹脂肪量，四肢筋量) が術後 6,12 か月時点における術前からの活動 量改善に影響するか否かを評価した。その結果, 周術期の活動量および活動量は術前と比較して 術後 1 か月で低下し（p<0.01）, 術後 6 か月以降 に術前より有意な改善を認めた $(\mathrm{p}<0.05$, Fig.2)。 これに対して患者立脚型アウトカムは客観的に

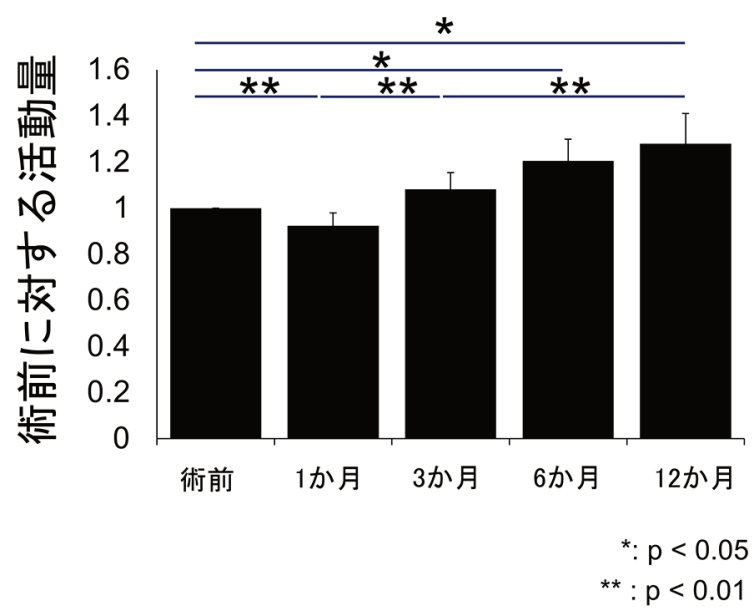

Fig.2 活動量の推移

術後 1 か月で活動量は優位に低下し, その後回復に転じ る。患者立脚型アンケートによる結果では術直後から回 復に転じていることを踏まえると (Table 1), 活動量によ る客観的結果とは乘離を認める。

収集・解析した活動量の変化とは異なり，全て の項目において術後 1 か月以降からの有意な改 善を示していた（Table 1)。特に RDQや ODI は活動数や活動量とは有意な相関を示さなかっ た。術前因子と活動量変化の関係を統計学的に 比較評価したところ, 術後 6 か月時の活動量己 善と術前の脂肪量が関連し，オッズ比は 0.64 , カットオフ值を $6.4\left(\mathrm{~kg} / \mathrm{m}^{2}\right)$ とすると $\mathrm{AUC}=$ 0.781 であった。また，術後各計測時点での活動 量は術前活動量に相関することから，本結果か ら, 術後活動量は術前活動量が高ければ維持さ れうることが示唆された（Table 2)。

\section{考察}

腕時計型ウエアラブル測定端末を用いて腰痛 患者の活動度を客観的に測定・評価し，腰痛患 者の実態について検証・検討を行った。

前腕に装着して計測した腰痛患者の活動度か ら，腰痛患者は健常者と比較し体幹の動きが有 意に低下していた。過去の報告でも腰痛患者に 
Table 1 患者立脚型アウトカムの推移

\begin{tabular}{lccccc}
\hline & 術前 & 1 か月 & 3 か月 & 6 か月 & 12 か月 \\
\hline JOABPEQ & & & & \\
疼痛 & $34.3 \pm 30.2$ & $56.5 \pm 40.5^{*}$ & $71.0 \pm 34.9^{*}$ & $61.6 \pm 36.8^{*}$ & $67.7 \pm 36.0^{*}$ \\
腰椎機能 & $46.8 \pm 29.7$ & $50.7 \pm 29.4$ & $58.3 \pm 28.6^{*}$ & $55.9 \pm 32.5^{*}$ & $63.4 \pm 30.9^{*}$ \\
歩行機能 & $20.5 \pm 20.3$ & $42.1 \pm 27.1^{*}$ & $46.4 \pm 30.2^{*}$ & $45.9 \pm 33.0^{*}$ & $45.9 \pm 30.2^{*}$ \\
社会生活 & $34.5 \pm 17.8$ & $44.9 \pm 22.0^{*}$ & $46.2 \pm 20.4^{*}$ & $45.1 \pm 23.8^{*}$ & $49.8 \pm 22.9^{*}$ \\
心理 & $38.0 \pm 19.6$ & $48.2 \pm 17.6^{*}$ & $48.3 \pm 15.9^{*}$ & $45.6 \pm 18.2^{*}$ & $47.0 \pm 14.7^{*}$ \\
ODI & $51.6 \pm 16.2$ & $35.8 \pm 17.0^{*}$ & $36.4 \pm 19.4^{*}$ & $37.0 \pm 20.8^{*}$ & $31.4 \pm 19.5^{*}$ \\
RDQ & $13.8 \pm 4.6$ & $9.8 \pm 5.7^{*}$ & $9.1 \pm 7.1^{*}$ & $9.5 \pm 7.0^{*}$ & $8.1 \pm 5.9^{*}$ \\
VAS & & & & $3.0 \pm 2.7^{*}$ & $3.7 \pm 3.2^{*}$ \\
腰痛 & $7.3 \pm 2.4$ & $3.7 \pm 3.3^{*}$ & $2.9 \pm 3.0^{*}$ & $3.2 \pm 3.3^{*}$ & $3.2 \pm 3.4^{*}$ \\
下肢痛 & $7.4 \pm 2.6$ & $3.5 \pm 3.4^{*}$ & $3.1 \pm 3.0^{*}$ & $3.8 \pm 3.4^{*}$ & $4.5 \pm 3.4^{*}$ \\
下肢疩れ & $7.2 \pm 2.6$ & $3.2 \pm 3.1^{*}$ & $3.6 \pm 3.4^{*}$ & & \\
\hline
\end{tabular}

術後 1 か月から各項目・ドメインにおいて有意な改善を示している。 ${ }^{*} \mathrm{p}<0.05$

Table 2 各夕イムポイントにおける活動量の相関解 析

\begin{tabular}{|c|c|c|c|}
\hline & & \multicolumn{2}{|c|}{ 活動量 } \\
\hline & & $\mathrm{r}$ & $\mathrm{p}$ 值 \\
\hline \multirow[t]{4}{*}{ 術 前 vs. } & 1 か月 & 0.6995 & $<0.001$ \\
\hline & 3 か月 & 0.7522 & $<0.001$ \\
\hline & 6 か月 & 0.7358 & $<0.001$ \\
\hline & 12 か月 & 0.7223 & $<0.001$ \\
\hline \multirow[t]{3}{*}{1 か月 vs. } & 3 か月 & 0.8899 & $<0.001$ \\
\hline & 6 か月 & 0.4475 & 0.019 \\
\hline & 12 か月 & 0.6472 & 0.002 \\
\hline \multirow[t]{2}{*}{3 か月 vs. } & 6 か月 & 0.6413 & $<0.001$ \\
\hline & 12 か月 & 0.7295 & $<0.001$ \\
\hline 6 か月 vs. & 12 か月 & 0.6380 & $<0.001$ \\
\hline
\end{tabular}

術後活動量はいずれのタイムポイントでも術後の活動 量を大きく反映し, 術後 1 か月の活動量は術後 3 か月 の活動量と相関し，その後の活動量の有意な向上に関 連していた。
おける体動数の低下が報告されていることか ら 6), 今回の計測はこのことを裏付ける結果と いえる。このことは腕時計型のデバイスを導入 することによって，被験者の日常生活動作を制 限することなく, かつ客観的に腰痛患者の活動 量を計測することが可能となることを意味して いる。

腰椎疾患患者の活動量と病態の関連を調べた ところ, JOABPEQのもつ一部の患者立脚型ア ウトカムにのみ活動量との関連を認め, さらに 腰椎疾患の活動量には腰痛だけでなく, BMI や筋量も影響を及ぼすことが示された。加速度 計を用いて評価した過去の研究によれば，腰痛 の急性期では活動量が減少するが慢性腰痛では 減少しないとされている7)。しかしながらその 詳細は不明であり，本研究が示したような性別 (男性であること), BMI 高值, 四肢筋量の低 下などの慢性腰痛における危険因子の具体的な 提示は臨床的に有意義であると言えよう。また, その他の研究によれば疼痛を生じると逃避行動 
によって疼痛部位を動かさなくなるが身体活動 とは関連しないと報告されており ${ }^{8}$, 腰痛患者 では疼痛により粗大な動きは制限されるため活 動数は低下するものの，全体としての活動量に 大きな変化は生じない可能性がある。

腰椎手術の術前後における活動度変化につい ての調查では, 患者の実際の活動量は術後 1 か 月に低下し, 術後 6 か月以降で改善がみられた。 一方で同一患者の JOABPEQ による評価では このような詳細な変化は検出されなかった。患 者立脚型アンケートにより術後活動を評価した 過去の報告でも同様に術後の活動量低下につな がる評価は報告されなかったことから ${ }^{9)}$ ，従来 型のアンケート型の主観的評価では実際の患者 の正確な活動量評価を行うことは限界があるこ とが示唆された。

また, 28 例の腰部脊柱管狭窄症患者の術前, 術後 6 か月の活動量を比較した他の研究では, 我々と同様に患者立脚型アウトカムとの関連は なく患者立脚型アウトカムや歩行速度は改善し たものの，活動量は術前と同等であったと報 告した ${ }^{10)}$ 。これは本研究と共通する点もある が術後半年での状態のみを横断的に評価したも のであり，腰椎手術患者をさらに縦断的に評価 した本研究は術前後の活動量を術後の客観的変 化と活動量の相関を縦断的に評価した点で有意 義である。さらに本研究において各期間の活動 量変化は病態, 術式によらず相関し, 特に術前 の活動量が術後活動量, さらには QOL 改善に 強く影響することが示唆された。術後成績に関 連する因子としては術前の BMI 高值およびこ れに関連し脂肪量高值が影響しており，身体活 動は筋肉量よりも脂肪量に影響されると報告し た研究が本研究の結果を支持するものと考え られる11)。

\section{まとめ}

腕時計型のウエアラブル端末装置を用いて, 腰痛患者の日常の活動量を計測・蓄積したデー 夕を用い，日常および手術前後における活動量 を客観的に評価することで腰痛患者の実態を評 価し患者立脚型アウトカムとの関連を調查した。 その結果, 活動量は JOABPEQ の腰椎機能, 社会生活の各ドメインと相関し, 腰痛 VAS 值 と負の相関を示した。さらに重回帰分析におい て腰痛 VAS 值，性別，BMI，四肢筋量と活動 量に相関を認めた。

腰椎手術前後の評価では，平均活動量は術前 と比較し術後 1 か月で低下, 術後 6 か月以降に 術前より有意に改善を示したほか，術前活動量 は術後の活動量に強い正の相関を認めた。一方 で患者立脚型アウトカムは全ての項目において 術後から線形に改善を認めており, ウエアラブ ル端末により取得した客観的な活動量の変化と は異なっていた。術前因子と活動量変化の関係 においては術後 6 か月時の活動量改善と術前の 脂肪量が関連し，オッズ比は 0.64 ， カットオフ 值を $6.4\left(\mathrm{~kg} / \mathrm{m}^{2}\right)$ とすると $\mathrm{AUC}=0.781$ であり， 新たな評価手法としての有効性を示唆している。 ウエアラブル端末を用いた腰痛患者の客観的な 活動量評価を行った本研究は, 患者の記憶や主 観に基づく従来型アンケート形式の評価と比較 するとより患者の穾態に即した新たな評価を与 える研究手法を与えるものと考えられる。

本研究は, 日本整形外科学会プロジェクト研究事 業の支援を受け 2016 年度から 2019 年度にかけ害 施された。

COI 開示

折田純久: 第一三共株式会社，日本イーライリリ 一株式会社, 塩野義製薬株式会社 
Novel lower back pain pathology using wearable trackers

\section{文 献}

1) Cole, R.J., Kripke, D.F., Gruen, W., Mullaney, D.J., Gillin, J.C., Automatic sleep/wake identification from wrist activity, Sleep, 15 (1992) 461469.

2) Inoue, M., Orita, S., Inage, K., Suzuki, M., Fujimoto, K., Shiga, Y., Kanamoto, H., Abe, K., Kinoshita, H., Norimoto, M., Umimura, T., Sato, T., Sato, M., Suzuki, M., Enomoto, K., Eguchi, Y., Aoki, Y., Akazawa, T., Ohtori , S., Comparison of the Activity Level of the Upper Limbs and Trunk in Patients with Low Back Pain Evaluated Using a Wearable Accelerometer: A Validation Study, Spine Surg. Relat. Res., 3 (2019) 354360.

3）折田純久, ウエアラブル端末とクラウド型デ ータベースによる次世代型デー夕を用いた腰 痛病態·治療効果関連評価の再構築に関わる 大規模縦断型調查, 日本整形外科学会プロジ エクト研究事業最終報告書, 2019.

4) Inoue, M., Orita, S., Inage, K., Suzuki, M., Fujimoto, K., Shiga, Y., Kanamoto, H., Abe, K., Kinoshita, H., Norimoto, M., Umimura, T., Sato, T., Sato, M., Suzuki, M., Enomoto, K., Eguchi, Y., Aoki, Y., Akazawa, T., Kawasaki, Y., Ohtori, S., Relationship between patient-based scoring systems and the activity level of patients measured by wearable activity trackers in lumbar spine disease, Eur. Spine J., 28 (2019) 1804-1810.

5) Inoue, M., Orita, S., Inage, K., Suzuki, M., Fujimoto, K., Shiga, Y., Kanamoto, H., Abe, K., Kinoshita, H., Norimoto, M., Umimura, T., Sato, T., Sato, M., Suzuki, M., Enomoto, K., Eguchi, Y., Akazawa, T., Aoki, Y., Kawasaki, Y., Ohtori, S., Objective evaluation of postoperative changes in real-life activity levels in the postoperative course of lumbar spinal surgery using wearable trackers, BMC Musculoskelet. Disord., 21 (2020) 72 .
6) Wilson, A.C., Palermo, T.M., Physical activity and function in adolescents with chronic pain: a controlled study using actigraphy, J. Pain, 13 (2012) 121-130.

7) Liszka-Hackzell, J.J., Martin, D.P., An analysis of the relationship between activity and pain in chronic and acute low back pain, Anesth. Analg., 99 (2004) 477-481, table of contents.

8) Vlaeyen, J.W., Linton, S.J., Fear-avoidance and its consequences in chronic musculoskeletal pain: a state of the art, Pain, 85 (2000) 317-332.

9) Elsamadicy, A.A., Adogwa, O., Warwick, H., Sergesketter, A., Lydon, E., Shammas, R.L., Mehta, A.I., Vasquez, R.A., Cheng, J., Bagley, C.A., Karikari, I.O., Increased 30-Day Complication Rates Associated with Laminectomy in 874 Adult Patients with Spinal Deformity Undergoing Elective Spinal Fusion: A Single Institutional Study, World Neurosurg., 102 (2017) 370-375.

10) Smuck, M., Kao, M.C., Brar, N., Martinez-Ith, A., Choi, J., Tomkins-Lane, C.C., Does physical activity influence the relationship between low back pain and obesity?, Spine J., 14 (2014) 209216.

11) Mikkola, T.M., von Bonsdorff, M.B., Salonen, M.K., Simonen, M., Pohjolainen, P., Osmond, C., Perälä, M.M., Rantanen, T., Kajantie, E., Eriksson, J.G., Body composition as a predictor of physical performance in older age: A ten-year follow-up of the Helsinki Birth Cohort Study, Arch. Gerontol. Geriatr., 77 (2018) 163-168.

Address for correspondence: Sumihisa Orita

Center for Frontier Medical Engineering,

Chiba University

1-33 Yayoi-cho, Inage-ku, Chiba 263-8522, Japan

※ 本稿は第 42 回日本疼痛学会（2020 年 12 月）「シ ンポジゥム 1 : 日本の疼痛研究をいかにすすめる べきか : 基礎，臨床，疫学を学ぶの講演内容を まとめたものである。 